Table 2. Clinical outcomes and adverse events

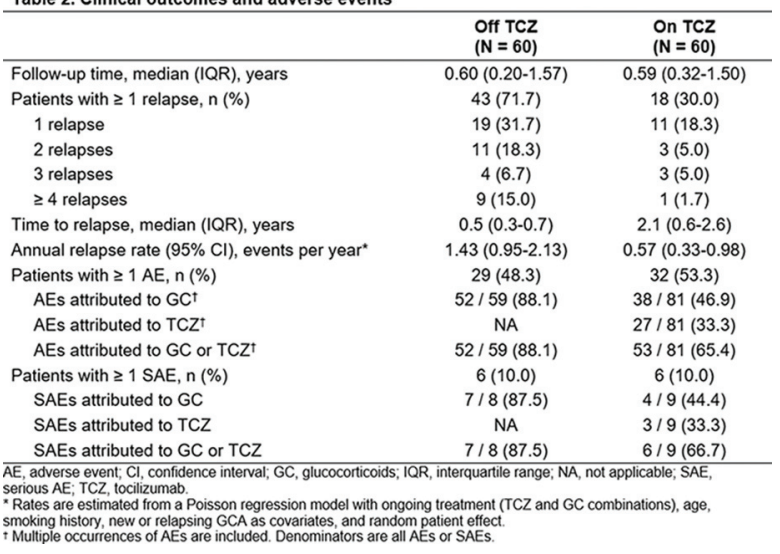

Disclosure of Interests: Sebastian Unizony Grant/research support from: F. Hoffmann-La Roche, Genentech, Consultant for: Kiniksa, Sanofi, GSK, Jinglan Pei Employee of: Genentech, Paris Sidiropoulos Employee of: Genentech, Jennie H. Best Shareholder of: Genentech, Employee of: Genentech, Christine Birchwood Employee of: Genentech, John H. Stone Grant/research support from: F. Hoffmann-La Roche, Genentech, Xencor, Consultant for: Chugain, F. Hoffmann-La Roche, Genentech, Xencor DOI: 10.1136/annrheumdis-2019-eular.1239

\section{SAT0249 IGA VASCULITIS ASSOCIATED WITH INFLAMMATORY BOWEL DISEASE. A RETROSPECTIVE STUDY}

Michel Villatoro Villarr ${ }^{1}$, Cynthia S. Crowson ${ }^{1,2}$, Ashima Makol ${ }^{1}$, Kenneth J. Warrington ${ }^{1}$, Steven R. Ytterberg ${ }^{1}$, Matthew Koster ${ }^{1} .{ }^{1}$ Mayo Clinic, Rheumatology, Rochester MN, United States of America; ${ }^{2}$ Mayo Clinic, Health Sciences Research, Rochester MN, United States of America

Background: Leukocytoclastic vasculitis has been reported in patients with inflammatory bowel disease (IBD) but cases of $\lg A$ vasculitis (IgAV) in IBD are considered rare.

Objectives: The purpose of this study was to describe the baseline characteristics and outcome of a series of patients with IBD and IgAV.

Methods: Biopsy-proven IgAV-patients with prior history of IBD were identified retrospectively at Mayo Clinic, Rochester, MN. Data were abstracted from direct medical chart review. Each IBD-IgAV case was matched to two controls with IgAV but without IBD history based on age, sex and baseline renal function at time of IgAV onset.

Results: A total of 9 patients were included in the study group (6 male, 3 female). Crohn's disease (CD) and Ulcerative Colitis (UC) were present in 7 and 2 patients, respectively. The mean length of time between IBD diagnosis and onset of $\operatorname{lgAV}$ was $17.3 \pm 19.9$ years. For patients on biologic treatment for IBD, the mean length of time between initiation of biologic and onset of IgAV was $3.3 \pm 3.8$ years (range $0-12$ years). Active IBD at IgAV-onset was present in $56 \%$ (5/9) of patients.

Tumor necrosis factor inhibitors (TNFi) were the most frequent biologics used for IBD (8, 89\%); infliximab was the most common (7, 78\%). At IgAV-onset, only 5 patients were on treatment with TNFi; two subsequently discontinued, two switched to another TNFi (adalimumab), and one patient continued. At last follow-up, two of three patients that remained on TNFi had full resolution of IgAV despite ongoing TNFi use. Comparison of baseline characteristics between cases with IBD-IgAV and matched non-IBD IgAV controls is demonstrated in Table 1. No differences were seen in regards to development of end-stage renal disease, resolution of hematuria and/or proteinuria, time to complete IgAV response or first $\lg \mathrm{AV}$ relapse.

Conclusion: Baseline characteristics and outcomes of patients with IBD$\lg A V$ are similar to those with IgAV without IBD. Development of IgAV is not limited to patients with clinically active IBD. Whether use of TNFi is related to the pathogenesis of IgAV in some patients with IBD remains unclear. Further research into the pathophysiologic connection between IBD and IgAV is needed.

\section{REFERENCES}

[1] Saint Marcoux B, De Bandt M. Vasculitides induced by TNFalpha antagonists: a study in 39 patients in France. Joint, bone, spine : revue du rhumatisme. 2006;73(6):710-3.
[2] Sy A, Khalidi N, Dehghan N, Barra L, Carette S, Cuthbertson D, et al. Vasculitis in patients with inflammatory bowel diseases: A study of 32 patients and systematic review of the literature. Seminars in arthritis and rheumatism. 2016;45(4):475-82.

[3] Ko JS, Uberti G, Napekoski K, Patil DT, Billings SD. Cutaneous manifestations in inflammatory bowel disease: a single institutional study of non-neoplastic biopsies over 13 years. Journal of cutaneous pathology. 2016;43 (11):946-55.

[4] Ozen S, Pistorio A, lusan SM, Bakkaloglu A, Herlin T, Brik R, et al. EULAR/PRINTO/PRES criteria for Henoch-Schonlein purpura, childhood polyarteritis nodosa, childhood Wegener granulomatosis and childhood Takayasu arteritis: Ankara 2008. Part II: Final classification criteria. Ann Rheum Dis. 2010;69(5):798-806

[5] Laresche C, Locatelli F, Biver-Dalle C, Nachury M, Heyd B, Koch S, et al. Severe Henoch-Schonlein purpura complicating infliximab therapy for ulcerative colitis. Cutis. 2017;99(1):E20-e2.

Table 1: Baseline characteristics of patients with inflammatory bowel disease and immunoglobulin-A vasculitis compared to patients with IgAV without inflammatory bowel disease

\begin{tabular}{|c|c|c|c|}
\hline Characteristic & $\begin{array}{c}\text { IBD- } \operatorname{lgAV} \\
(\mathrm{n}=9)\end{array}$ & $\begin{array}{c}\text { Non-IBD } \lg A V \\
(n=18)\end{array}$ & $p$-value \\
\hline Age at IgAV diagnosis, years ${ }^{\star}$ & $40.8 \pm 17.5$ & $40.7 \pm 17.4$ & 0.96 \\
\hline Male sex & $6(67 \%)$ & $12(67 \%)$ & 1.00 \\
\hline Length of follow-up, years* & $1.3 \pm 2.6$ & $1.1 \pm 1.2$ & -- \\
\hline Creatinine, $\mathrm{mg} / \mathrm{dL}^{*}$ & $1.0 \pm 0.4$ & $0.9 \pm 0.3$ & 0.59 \\
\hline eGFR $\left(\mathrm{ml} / \mathrm{min} / 1.73 \mathrm{~m}^{2}\right)^{\star}$ & $91.4 \pm 31.6$ & $96.4 \pm 22.9$ & 0.72 \\
\hline C-reactive protein, $\mathrm{mg} / \mathrm{L}^{*}$ & $23.3 \pm 12.2$ & $27.0 \pm 27.4$ & 0.62 \\
\hline Renal involvement & $7(78 \%)$ & $10(56 \%)$ & 0.26 \\
\hline Microscopic hematuria & $5(56 \%)$ & $7(39 \%)$ & 0.41 \\
\hline Proteinuria & $7(78 \%)$ & $8(44 \%)$ & 0.10 \\
\hline Palpable purpura & $9(100 \%)$ & $18(100 \%)$ & 1.00 \\
\hline Abdominal Ischemic symptoms & $3(33 \%)$ & $2(11 \%)$ & 0.161 \\
\hline \multicolumn{4}{|l|}{ Disease status at $\lg A V$ diagnosis } \\
\hline Active IBD & $5(56 \%)$ & - & - \\
\hline TNF- $\alpha$ inhibitor at diagnosis & $2 / 5(40 \%)$ & - & - \\
\hline - Ever TNF- $\alpha$ inhibitor & $5 / 5(100 \%)$ & - & - \\
\hline Inactive IBD & $4(44 \%)$ & - & - \\
\hline TNF- $\alpha$ inhibitor at diagnosis & $3 / 4(75 \%)$ & - & - \\
\hline - Ever TNF- $a$ inhibitor & $3 / 4(75 \%)$ & - & - \\
\hline
\end{tabular}

IBD, inflammatory bowel disease; IgAV, immunoglobulin-A vasculitis; eGFR, estimated glomerula filtration rate; TNF- $\alpha$, tumor necrosis factor- $\alpha$ inhibitor.

"Mean \pm standard deviation

Disclosure of Interests: None declared DOI: 10.1136/annrheumdis-2019-eular.7413

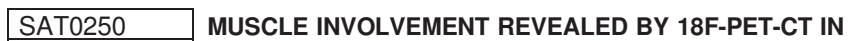 POLYMYALGIA REUMATICA}

Daniel Wendling ${ }^{1}$, Maxime Sondag ${ }^{1}$, Nicolas Giraud ${ }^{1}$, Mickaël Chouk ${ }^{1}$, Hatem Boulahdour ${ }^{2}$, Clément Prati ${ }^{1}$, Frank Verhoeven ${ }^{1} .{ }^{1} \mathrm{CHRU}$, Rheumatology, Besançon, France: ${ }^{2} \mathrm{CHRU}$, Nuclear Medicine, Besançon, France

Background: Imaging techniques in polymyalgia reumatica (PMR) have revealed mainly bursitis, tenosynovitis, capsulitis and enthesitis. This is also the case for 18F-FDG-PET-CT. This technique, which has shown its interest in the diagnosis of PMR, allows an assessment of the metabolic activity of the entire musculoskeletal system and in particular of muscle structures.

Objectives: The objective of this work was to evaluate muscle damage using 18F-FDG-PET-CT in PMR.

Methods: This is a retrospective study including patients with PMR (ACR EULAR 2012 criteria) seen in our department, who had an 18F-FDG PET-CT examination between September 2012 and November 2018. A control group consisting of subjects without rheumatological manifestations who had such an examination as part of neoplastic research or neoplastic disease control was also evaluated. PET evaluation included 17 sites suggestive of PMR, as previously reported [1], leading to a global PET score ranging from 0 to 51 . Muscle hypermetabolism areas were similarly rated according to the same Goerres classification [2] $(0=$ no uptake; 1 = slight uptake, less than liver; 2 = uptake like liver; $3=$ uptake higher than liver). Muscle activity sites have been identified. A comparison of PMR patients with and without muscle involvement was performed using the Mann Whitney or Fisher's exact test. 
Results: 134 cases were reviewed, concerning 80 PMR (mean age 67.9) and 54 "controls" (mean age 68.1). Overall, PET muscle damage was observed in 27 cases (34\%) in PMR and 6 cases $(11 \%)$ in controls $(p=0.004)$. The damage is bi or multi-focal in $16 / 27$ cases. The affected sites are: thighs and ischium-leg $(n=10)$, spinal $(11)$, piriform/buttocks (7), pectoral (5), large serrated (4), subspinatus/subscapular (3), deltoid (1), trapezius (1). Fasciitis was found in 4 cases. As expected, PMR patients exhibited higher TEP scores than controls $(p<0.001)$. In PMR patients, PET muscle involvement was associated with higher ESR values $(p<0.05)$, but not with age, CRP or global PMR PET score.

Conclusion: Muscle involvement assessed by 18F-Fluorodeoxyglucose PET-CT is frequent in PMR (1/3), located at usual sites of symptoms of the disease, without association with age, CRP levels or global PET score for PMR. Muscle should be carefully evaluated during PET in cases of PMR; these pictures may be a new diagnosis feature of the disease.

\section{REFERENCES}

[1] Sondag.M, et al. Rheumatology 2016;55(8):1452-7.

[2] Goerres GW, et al. Clin Nucl Med 2006;31:386-90.

Disclosure of Interests: None declared

DOI: 10.1136/annrheumdis-2019-eular.5256

\section{SAT0251 SEX- AND AGE-RELATED DIFFERENCES IN CLINICAL MANIFESTATIONS OF BEHÇET'S DISEASE IN A LARGE COHORT OF CHINA PATIENTS}

LI Chaoran ${ }^{1}$, Xiuhua Wu ${ }^{1,2}$, Jing Shi ${ }^{1}$, Lu LI ${ }^{1}$, Jinjing Liu ${ }^{1}$, Xiaofeng Zeng ${ }^{1}$, Wenjie Zheng $1 .{ }^{1}$ Peking Union Medical College Hospital, Department of Rheumatology, Beijing, China; ${ }^{2}$ General Hospital of Tianjin Medical University, Department of Rheumatology, Tianjin, China

Background: Behçet's disease $(\mathrm{BD})$ is a systemic vasculitis with multiple symptoms such as recurrent oral and/or genital ulceration, skin lesions, ocular lesions, and other systems affection. Studies have been conducted to reveal sex- and age-related differences in clinical characteristics of BD in several countries ${ }^{1-5}$, but up to now sex and age influence for Chinese BD patients is very limited.

Objectives: This study aimed to investigate the clinical phenotypes of BD concerning gender and age in China.

Methods: We retrospectively reviewed the medical records of BD patients followed up in the Departments of Rheumatology, Peking Union Medical College Hospital (PUMCH) between March 2014 and January 2019. Demographics, clinical features at onset and during follow-up were obtained from a review of medical records.

Results: A total of 489 BD patients were included in our database: 286 males $(58.49 \%)$ and 203 females $(41.51 \%$ ) (Sex ratio $M / F$ was 1.41 ), with a median age of 34 years (interquartile range: 28-44 years). Recurrent oral ulceration was the most common manifestation (96.32\%), followed by genital ulceration $(71.17 \%)$, skin lesions $(57.67 \%)$, vascular lesions (25.36\%), and ocular involvement (24.13\%). Gastrointestinal (GI) involvement $(15.13 \%)$, positive pathergy test $(14.11 \%)$, and neurological involvement $(5.93 \%)$ were less frequently observed. The comparative study between males and females revealed that ocular lesions $(28.67 \%$ vs $17.73 \%, P=0.005)$, vascular lesions $(31.47 \%$ vs $16.75 \%, P<0.001)$ and positive pathergy test $(17.83 \%$ vs $8.37 \%, P=0.002)$ were more common in male, while genital ulceration was more common in female (64.34\% vs $80.79 \%, P<0.001)$. Regarding age difference, ocular lesions $(\mathrm{P}=0.017)$ were more frequently observed in younger patients, while vascular lesions $(P=0.024)$ and $G$ l symptoms $(P=0.010)$ were more common in older patients. Gender differences of these manifestations were more prominent in certain age groups among 20-50 years old than other groups.

Conclusion: These analyses support that the clinical features of Chinese $\mathrm{BD}$ were different depending on sex and age.

\section{REFERENCES}

[1] Bonitsis, NG. et al. Gender-specific differences in Adamantiades-Behçet's disease manifestations: an analysis of the German registry and meta-analysis of data from the literature. Rheumatology 2015. 54, 121.

[2] Ishido, T. et al. Clinical manifestations of Behçet's disease depending on sex and age: results from Japanese nationwide registration. Rheumatology 2017. 56,1918-1927.
[3] Ugurlu, N. et al. The natural course and factors affecting severity of Beh çet's disease: a single-center cohort of 368 patients. Rheumatol Int 2015. 35, 2103-7

[4] Khabbazi A, et al. Demographic and clinical features of Behcet's disease in Azerbaijan. Int J Rheum Dis 2014. 21,1114-1119.

[5] Hamzaoui, A. et al. Comparison of clinical features of Behcet disease according to age in a Tunisian cohort. Acta Med Iran 2014,52,748.

Disclosure of Interests: None declared

DOI: 10.1136/annrheumdis-2019-eular.4742

\section{Scleroderma, myositis and related syndromes}

\section{SAT0252 AN EVALUATION OF THREE DIFFERENT METHODS TO EVALUATE SKIN IMPAIRMENT IN SYSTEMIC SCLEROSIS PATIENTS}

Barbara Ruaro ${ }^{* 1}$,Vanessa Smith ${ }^{2}{ }^{4}$, Sabrina Paolino ${ }^{1}$,Carmen Pizzorni ${ }^{1}$, Stefano Soldano ${ }^{1}$, Andrea Casabella $^{1}$, Massimo Patanè $^{1}$,Elisa Alessandri ${ }^{1}$, Alberto Sulli ${ }^{1}$,Maurizio Cutolo ${ }^{1}{ }^{1}$ Research Laboratory and Academic Division of Clinical Rheumatology, Department of Internal Medicine, University of Genova, IRCCS San Martino Polyclinic Hospital, Genoa, Italy, ${ }^{2}$ Department of Rheumatology, Ghent University Hospital, Ghent, Belgium; ${ }^{3}$ Department of Internal Medicine, Ghent University, Ghent, Italy, 4Unit for Molecular Immunology and Inflammation, VIB Inflammation Research Center (IRC), Ghent, Belgium

Background: One of the characteristics of systemic sclerosis (SSc) is an increase in dermal thickness (DT) (1-3). Although the standard method to evaluate the extent of skin involvement is the modified Rodnan skin score (mRSS) (3,4), high frequency ultrasounds (US) and the plicometer skin test (Plicometry) (5-8) are now being used in SSc patients.

Objectives: The aim of this study was to determine any correlations between mRSS, US and Plicometry during the evaluation of skin impairment in SSc patients.

Methods: A total of $63 \mathrm{SSc}$ patients (mean age 64 $\pm 13 \mathrm{SD}$ years, mean SSc duration $7 \pm 6$ years) and 63 healthy subjects (HS) (mean age 64 $\pm 12 S D$ years) were enrolled.

The three methods (mRSS, US and Plicometry) were used to evaluate skin impairment in the seventeen areas of the skin usually evaluated by mRSS (face, fingers, dorsum of hands, forearms, arms, chest, abdomen, thighs, legs and feet) and the total score was calculated, as previously reported $(1,3,4,8)$. Intra-rater reliability of the three techniques was assessed by having the same rater performing 2 consecutive measurements at each skin site. Statistical evaluation was performed by nonparametric tests.

Results: A significant positive correlation was observed between the three methods used to evaluate DT in the SSc patients (mRSS vs US $r=0.64$ $p<0.0001 ;$ mRSS vs Plicometry $r=0.97, \quad p<0.0001 ;$ US vs Plicometry $r=0.55, p<0.0001)$. Conversely, there was no correlation between these parameters in the CNT group ( $p>0.05)$. The intraclass correlation coefficients for mRSS was $0.95,0.97$ for US and 0.96 for Plicometry. Data collection for mRSS took almost 10 minutes, 15 minutes for Plicometry and 20 minutes for US.

Conclusion: This study demonstrates a significant relationship between mRSS, US and Plicometry in the DT evaluation of SSc patients. The SSc patients had statistically significantly higher values than HS when the 3 techniques were used to evaluate the seventeen skin areas.

\section{REFERENCES:}

[1] Cutolo M, et al. Best Pract Res Clin Rheumatol. 2016;30:670-687.

[2] Ruaro B, et al. Arthritis Rheumatol 2015; 67 (suppl 10).

[3] Clements P, et al. J Rheumatol 1995:22:1281-5.

[4] CzirjákL, et al. Ann Rheum Dis. 2007; 66: 966-9.

[5] Hesselstrand R, et al. Rheumatology 2008;47:84-7.

[6] Kaloudi O, et al. Ann Rheum Dis. 2010;69:1140-3.

[7] Ruaro B, et al. Microvasc Res. 2018;115:28-33.

[8] Parodi MN, et al. Br J Rheumatol. 1997;36:244-50.

Disclosure of Interests: None declared

DOI: 10.1136/annrheumdis-2019-eular.1739 